\title{
Structural family factors and bullying at school: a large scale investigation based on a Chinese adolescent sample
}

\author{
Haoran Wang ${ }^{1 \dagger}$, Yuanyuan Wang ${ }^{2 \dagger}$, Guosheng Wang ${ }^{3 \dagger}$, Amanda Wilson ${ }^{2}$, Tingting Jin ${ }^{3}$, Longjun Zhu ${ }^{3}$, \\ Renjie Yu ${ }^{3}$, Shuilan Wang ${ }^{3}$, Weijia Yin ${ }^{3}$, Huihui Song ${ }^{3}$, Shun Li ${ }^{4}$, Qiufang Jia ${ }^{3}$, Xiaobin Zhang ${ }^{3}$ and Yong Yang ${ }^{3 *}$
}

\begin{abstract}
Backgrounds: Various family factors have been identified in association with school bullying and the involvement of children and adolescents in bullying behaviors.

Methods: A total of 11,919 participants (female $=6671$, mean age $=15$ ) from 22 middle schools in Suzhou City, China completed the questionnaire. The associations between structural family factors (family socio-economic status, living arrangement, number of siblings, whether they were local residents/migrants, had an urban/rural hukou [a household registration system in China], parental and maternal education levels, and other various bullying-related constructs (i.e. bullying witnessing, bullying involvement, bystander intervention, and fear of being bullied) were all examined. Odds ratios (ORs) adjusted for covariates were calculated for the four bullying-related constructs (bullying witness, bullying involvement, bystander intervention, and reactions to being bullied) using structural family factors.

Results: The result showed that all demographic household characteristics were associated with bullying at school except for being from a single-child family. Adolescents from rural families witnessed more bullying incidents than those from local families $(\mathrm{OR}=1.35,95 \% \mathrm{Cl}$ : $[1.09,1.68])$. Adolescents who come from migrant families $(\mathrm{OR}=1.12,95 \%$ $\mathrm{Cl}:[1.07,1.43])$ with a rural hukou $(\mathrm{OR}=1.31,95 \% \mathrm{Cl}:[1.00,1.74])$ and low parental education levels $(\mathrm{OR}=1.42,95 \%$ $\mathrm{Cl}:[1.01,2.57])$ were more likely to be bullies. Adolescents who came from migrant families $(\mathrm{OR}=1.37,95 \% \mathrm{Cl}$ : $[1.03$, 1.82]), with low maternal education levels $(\mathrm{OR}=1.42,95 \% \mathrm{Cl}$ : $[1.06,1.91])$ engaged in more negative bystander intervention behaviors. Furthermore, adolescents with less educated mothers experienced a higher fear of being bullied (never versus sometimes: $\mathrm{OR}=1.33,95 \% \mathrm{Cl}$ : [1.00, 1.85]; never versus usually $\mathrm{OR}=1.39,95 \% \mathrm{Cl}$ : [1.01, 1.20]).

Conclusions: A systematic examination of the relationship between school bullying and demographic household characteristics may be used to inform school policies on bullying, such as training management on the importance of paying attention to adolescents from disadvantage household backgrounds. Identifying demographic factors that may predict bullying can also be used to prevent individuals from becoming involved in bullying and reduce the related negative consequences from being bullied.
\end{abstract}

Keywords: Adolescents, Bullying, Socio-economic status

*Correspondence: szgjyy@126.com

†Haoran Wang, Yuanyuan Wang and Guosheng Wang contributed equally to this work.

${ }^{3}$ Suzhou Guangji Hospital, 11\# Guangqian Road, Suzhou 215137, China

Full list of author information is available at the end of the article

\section{Introduction}

School bullying has been widely identified as a risk factor for adolescents' poor psychological wellbeing and a major challenge for school management. It is estimated that the percentage of students involved in bullying 
ranges from 8 to 40\% [1]. In China this number is estimated to be nearly $20 \%$ [2]. Considering the pervasive and detrimental effects of bullying on the psychosocial development of adolescents [3], it is necessary to further explore both the risk and protective factors of school bullying. Previous literature has showed that socio-demographic factors, including sex, race, age, family socio-economic status etc. may influence the risk of bullying on campus [4].

Family systems have long been recognized as a source of influence on adolescents' social behaviors at school, including aggressive behaviors like bullying [5]. Previous studies have shown that several family characteristics are closely related to school bullying, such as family environments, parent-child relations, and family norms [6]. Family environments have been conceptualized as a multi-component factor including general feelings of safety at home, perceived parental support, and so forth [7]. Previous research has further found that negative family environments may be associated with higher risks of bullying victimization at school [7]. Oliveira and colleagues [8] found that positive family interactions may protect adolescents from being involved in school bullying (both as perpetrators and victims). Evidence also shows that adolescents who have good relationships with their parents are less likely to be bullies or victims [9]. Also, Orozco-Vargas [10] found that family moral values were closely related to the likelihood of being bullied among adolescent girls.

Living in a multi-generation family could also be associated with bulling at school. Research has shown that grandparents' involvement in the family education could be associated with less adjustment problems for adolescents [11]. Zhang [12] found that co-habiting with grandparents could significantly facilitate adolescents' academic performance, which is also a well-established protective factor that buffers against involvement in school bullying. Considering the positive effects of grandparents' involvement, further studies are needed to examine the protective effects of living with grandparents on involvement into school bullying.

Having siblings has also been identified as a protective factor for school bullying. Living in a single child family could significantly influence adolescents' social adjustment at school [13], which is closely related to school bullying [14]. However, such influence is complex. On the one hand, single-child families are prone to overly attending to the only child, which could hinder normal social development and lead to maladjustments, such as peer conflicts and loneliness [15]. On the other hand, single-child families are able to allocate more resources to the only child and thus could enhance the general well-being of the child (Yang J: Has the one-child policy improved adolescents educational wellbeing in China?, Unpublished).

Besides, there are various other household demographic characteristics, such as family structures and socio-economic status that could also be related to school bullying [16]. For example, Ackerman and colleagues [17] found that adolescents from unmarried families or cohabiting families are more likely to engage in delinquent and aggressive behaviors, such as bullying. Similarly, Fung and colleagues [18] found that adolescents from single-mother or step-mother families engaged in more aggressive behaviors compared to their counterparts. Previous evidence also showed that adolescents from a disadvantageous socio-economic background (e.g. lower household incomes, lower parental/maternal education level, and living in rural areas) scored higher on traits like impulsivity and showed more anti-social behaviors than their socio-economically advantaged counterparts [19]. However, more recent evidence suggests that family characteristics do not act as predictors to involvement in school bullying [20]. These inconsistent findings about the effects of household characteristics on bullying warrant further investigation.

Moreover, the relationships between household demographics, Chinese culture, and bullying have had little exploration. For example, single child family is defined as a family composed of one child [21]. As the "one-child" policy was enforced in China since 1979, being a singlechild family is predominant in urban areas of China [21]. It is important to note that China now operates under a 'two-child' policy since 2015 [22]. While the current urban families of China is skewed towards having an only child, it is likely that in the future, due to the two and three child policy changes, that there will be a more diverse range of family compositions in China. Internal migrant family is defined as rural households who have moved to Chinese cities [23]. Due to large-scale migration of Chinese families from rural areas to cities in the last two decades, internal migrant families are much more prevalent in China than in Western countries [23]. This suggests that migration is then an important sociodemographic characteristic in the Chinese context, and thus Western research cannot be applied to China without adaption due to the difference in the number of internal migrants. Multi-generation family refers to families that consist of more than two generations in one household. Again it is more prevalent in China than in Western countries as part of China's cultural traditions [24]. It is therefore necessary to examine whether adolescents from these types of families are more or less likely to be involved in school bullying. Previous evidence showed that living in an internal migrant family could be associated with the probability of adolescents' involvement 
in bullying. One recent investigation [25] showed that adolescents from such families are more likely to perpetrate bullying than their local counterparts. However, there is also research evidence [26] suggests that internal migrated adolescents did not experience more peer problems than non-migrant adolescents. Again, considering such inconsistencies in the literature, whether being a single child and living in an internal migrant family and how this could be related to adolescents' bullying experience at school should be further explored.

Taking into consideration the contradicting findings above and the need for examining school bullying in the Chinese cultural context, there are several gaps in the literature that this study aims to address. First, the relationships between some Chinese household types (e.g. single-child family, intergenerational family, internal migrated family) and bullying have rarely been explored in research. Second, most of the studies focus only on the association between family structures and the roles in bullying (i.e. bully, victim, and bully/victim), which neglects other bullying-related constructs [27]. In order to fill this gap in the literature, the current research focused on the association between household demographic characteristics and a full range of bullying indicators including: bullying witnessing, bullying involvement, bystander intervention, and reactions to being bullied. The researchers hypothesized that: (1) low paternal/maternal education levels and holding a rural hukou would be associated with a higher risk of being bullied or bullying others at school; (2) living in a multigenerational family could be associated with a lower risk of being bullied or bullying others at school. Associations between other household family demographics and bullying-related constructs could not be predicted due to the paucity of research evidence so far.

\section{Methods}

\section{Participants}

In January 2019, 22 middle schools (grades 7-11) in Suzhou, a major city in Eastern China, were invited to participate in the research, with no school declining the invitation to participate. Cluster sampling methods were used to select middle and high schools in one of the districts in Suzhou City. A total of 11,919 questionnaires were returned with the response rate being $83.2 \%$. Assent was obtained from participates and passive informed consent was obtained from their main guardian prior to the pencil-and-paper questionnaires being filled in at school. Teachers were involved in obtaining passive parental consents and an information sheet was given to parents/guardians allowing them the opportunity to consider whether their child should take part in the study and providing them the opportunity to inform the teacher if they did not want their child to participate. If the parent did not inform the teacher that they objected to the research, it was passively assumed that the teacher had their consent for the child to participate (Hollmann \& McNamara, 1999). A non-anonymous survey format was adopted in the current research. Participants were instructed to sign their name on the questionnaire and were assured that their name would be kept confidentially. The data inputted was anonymous to the research team. The research was approved by the Ethics Committee of the Mental Health Center of Suzhou (approval SGLS2017-037).

\section{Measures \\ Social demographics checklist}

The socio-demographic collected included: (1) sex and age; (2) rural/urban hukou; (3) migrant status (local residence/moved from other areas of China); (4) living arrangement (living with parents/grandparents/other relatives); (5) education level of parents; (6) family economic status. Considering the difficulty for adolescents to report the household income precisely, we used an item "are you living in your own house or in a rented house?" to roughly measure their family economic status; and finally we collected information on (7) being a single child or having sibling(s).

\section{Bullying questionnaire}

Items in the bullying questionnaire include: (1) Bullying Witness: "During this school year how often have you seen someone being bullied?" (2) Bullying Involvement: "During this school year how often have you been bullied at school?" and "During this school year how often have you bullied others?" (3) Bystander Intervention: "If you saw bullying at school, what would you do?", bystander reactions were classified as not-intervening (i.e. look on and do nothing), negatively intervening (teasing those who were being bullied), and positively intervening (helping those who were being bullied). (4) Fear of Being Bullied: "During the past year how often did you miss school because you felt unsafe, uncomfortable, or nervous at school or on your way to/from school?" In the current research, two traditional forms of bullying, verbal insult (i.e. teasing) and physical assaults (i.e. pushing, shoving, kicking, slapping or hitting) were measured [28].

\section{Statistical analysis}

All statistical analyses were conducted using SPSS 26.0 and Mplus 7.0. Considering the hierarchical nature of the data (i.e. individuals nested into schools), multilevel regression modeling was used to take possible clustering effects into consideration. First, intra-class correlations (ICCs) were calculated to determine the degree of 
homogeneity of the outcome variables within the clusters [29]. Then, the two-level logistic regression models with random intercepts [30] were estimated and multivariateadjusted odds ratios (ORs) for the four bullying-related constructs (bullying witness, bullying involvement, bystander intervention, and reactions to being bullied) were calculated with the various socio-demographic characteristics of family households.

As bullying witnessing and fear of being bullied were coded as an ordinal categorical variable (never, sometimes, usually, and almost every day), a parallel line test was conducted to examine whether the associations between predictive and outcome variables were different across categories.

\section{Results}

\section{Preliminary results}

Sample characteristics are shown in Table 1. Results showed that $26.4 \%$ of boys and $14.3 \%$ of girls had been involved in bullying at least once in this study and all participants were classified in four categories using a dichotomous response of yes or no to each of the four categories: bullies $(n=1515,12.7 \%)$, victims $(n=463$,

Table 1 Characteristic of the participants

\begin{tabular}{ll}
\hline Demographic information & N (\%) \\
\hline Sex & \\
Female & $5486(46.02 \%)$ \\
Male & $6433(53.98 \%)$ \\
Age (Means and Standard Deviations.) & $15.0(1.47)$ \\
Migrant status & \\
Local & $4832(37.71 \%)$ \\
Migrant from other areas of China & $4495(40.54 \%)$ \\
Hukou status & \\
Urban hukou & $6735(56.50 \%)$ \\
Rural hukou & $4399(36.91 \%)$ \\
Living arrangement & \\
Living with parents & $11,206(94.01 \%)$ \\
Living with grandparents & $369(3.09 \%)$ \\
Living with other relatives & $208(2.90 \%)$ \\
Single child or not & \\
Being the single child & $7666(64.31 \%)$ \\
Not being the single child & $4006(34.4 \%)$ \\
Paternal education level & \\
Middle school or lower & $5778(48.8 \%)$ \\
Senior high or vocational school & $3672(31.0 \%)$ \\
Bachelors or higher & $2394(20.2 \%)$ \\
Maternal education level & \\
Middle school or lower & $6650(56.2 \%)$ \\
Bachior high or vocational school & $3126(26.4 \%)$ \\
\hline & $2067(17.5 \%)$ \\
\hline
\end{tabular}

$3.9 \%)$, bully/victim $(n=480,4.0 \%)$, and participants not involved in bullying $(n=9461,79.4 \%)$.

Results showed that ICCs for all four dependent variables (bullying witnessing, bullying involvement, fear of being bullied, bullying intervention) ranged from 0.020 to 0.043 , which means that 2 to $4.3 \%$ of the variation in the dependent variables could be attributed to the variation of level-2 variable (i.e. school).

\section{Family characteristics and bullying witnessing}

Odds ratios (ORs) for bullying witnessing are listed in Table 2. A parallel line test showed that the associations between family characteristics and witnessing bullying were not different across categories $(p=0.51)$. Results showed that adolescents who came from rural families witnessed more bullying scenarios than those who came from urban families (never versus often $\mathrm{OR}=1.35,95 \%$ CI: $[1.09,1.68])$. Other family demographics (family status, economic status, etc.) were not related to witnessing bullying.

\section{Family characteristics and bullying involvement}

Adjusted ORs for bullying involvement are listed in Table 3. Results showed that adolescents who come from migrant families $(\mathrm{OR}=1.12,95 \% \mathrm{CI}$ : $[1.07,1.43])$ with a rural hukou (OR=1.31, 95\% CI: [1.00, 1.74]), and low parental education levels $(\mathrm{OR}=1.42,95 \% \mathrm{CI}$ : $[1.01,2.57])$ were more likely to be bullies. Coming from migrant families was the only factor that was related to the higher likelihood of being a bully/victim $(\mathrm{OR}=1.23,95 \% \mathrm{CI}$ : $[1.06,1.43])$. No factors in the current research were associated with the likelihood to be a victim.

\section{Family characteristics and bystander intervention}

ORs for bystander intervention are listed in Table 4. Results showed that adolescents who came from migrant families $(\mathrm{OR}=1.37,95 \% \mathrm{CI}$ : $[1.03,1.82])$ with low maternal education levels $(\mathrm{OR}=1.42$, 95\% CI: $[1.06,1.91])$ engaged in more negative intervention based behaviors such as teasing those who were bullied. Other family factors (family status, economic status, etc.) were not associated with bullying intervention.

\section{Family characteristics and fear of being bullied}

Adjusted ORs for fear of being bullied are listed in Table 5. A Parallel line test showed that the associations between family factors and witnessing bullying were not different across categories $(p=0.66)$. Results showed that adolescents with a less educated mother suffered higher levels of fear of being bullied (never versus sometimes: $\mathrm{OR}=1.33$, 95\% CI: [1.00, 1.85]; never versus usually 
Table 2 Odds ratios for bullying witnessing

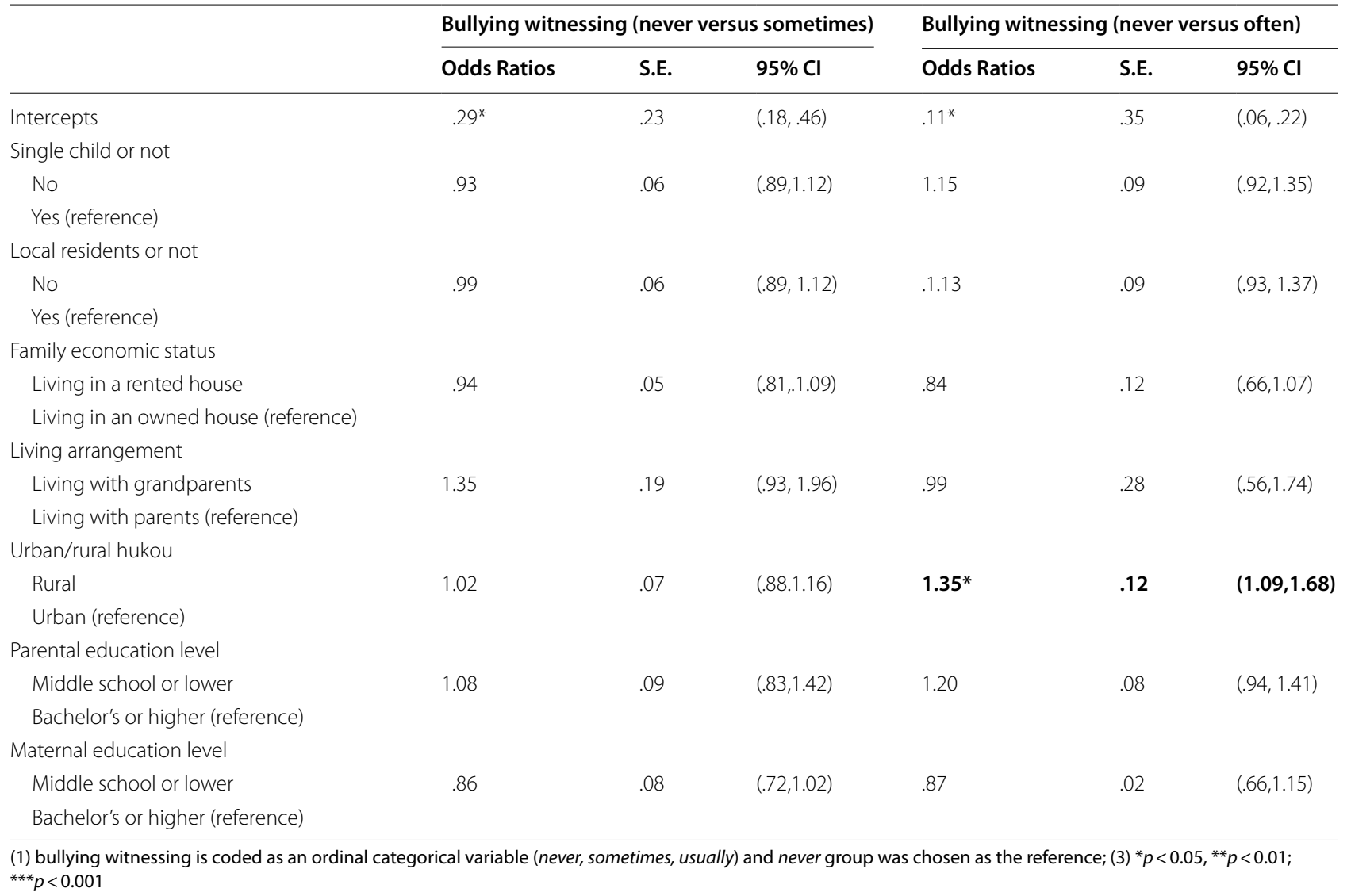

$\mathrm{OR}=1.39$, 95\% CI: $[1.01,1.20])$. Other family factors were not associated with fear of being bullied in the current study.

\section{Discussion}

In the current research, the associations between household socio-demographic characteristics including family migrant status (migrants/non-migrants), hukou status (urban/rural hukou), parental/maternal education level, and living arrangements were explored in relation to four bullying-related constructs. Results indicated that the aforementioned demographic factors were closely related to adolescents' bullying behaviors at school. To the best of our knowledge, this is the first research study to systematically examining the relations between family demographics and bullying-related constructs.

This study found that migrant status (migrants/local residents) was the only sociodemographic factor associated with bullying witnessing, with adolescents from migrant families observing more incidents of bullying at school. Previous research has also shown that migrant adolescents do not have equal access to various social welfare services (i.e. entrance to public schools and health care) compared to their urban counterparts, and they are also more likely to experience peer exclusion or discrimination [31]. Previous evidence showed that individuals who witnessed bullying scenarios were more likely to get involved in bullying than counterparts [32]. Together with the current results, it could be suggested that the disadvantages faced by migrant adolescents may render them more susceptible to school bullying. Further research is required to explore the impact of migrant status on bullying in schools to better understand this finding.

As hypothesized, being migrants, holding rural hukou, and low parental education levels were positively associated with the risk of being bullies (or bully/victims). This result is consistent with previous findings which show that having a low household income and low parental social statuses are predictive of delinquency during adolescence [33]. Migrant adolescents may hold different social norms than their local counterparts, and intolerance to customary differences may instigate a bully environment in schools. Research further shows that bullying behaviors may have different implications for rural and urban adolescents. As shown in the current study and 
Table 3 Odds ratios for bullying involvements

\begin{tabular}{|c|c|c|c|c|c|c|c|c|c|}
\hline & \multicolumn{3}{|c|}{ Victimization } & \multicolumn{3}{|c|}{ Perpetration } & \multicolumn{3}{|c|}{ Perpetration- victimization } \\
\hline & OR & SE & $95 \% \mathrm{Cl}$ & OR & SE & $95 \% \mathrm{Cl}$ & OR & SE & $95 \% \mathrm{Cl}$ \\
\hline Intercept & $.14^{* *}$ & .18 & $(.11, .17)$ & $.29 * *$ & .45 & $(.19, .44)$ & $.06^{* *}$ & .28 & $(.42, .87)$ \\
\hline \multicolumn{10}{|l|}{ Single child or not } \\
\hline No & .84 & .12 & $(.66,1.08)$ & 1.12 & .10 & $(.86,1.45)$ & .95 & .12 & $(.82,1.09)$ \\
\hline \multicolumn{10}{|l|}{ Yes (reference) } \\
\hline \multicolumn{10}{|l|}{ Local residents or not } \\
\hline No & .99 & .13 & $(.77,1.28)$ & $1.12^{*}$ & .11 & $(1.07,1.43)$ & $1.23^{*}$ & .13 & $(1.06,1.43)$ \\
\hline \multicolumn{10}{|l|}{ Yes (reference) } \\
\hline \multicolumn{10}{|l|}{ Family economic status } \\
\hline Living in a rented house & 1.04 & .16 & $(.75,1.43)$ & .92 & .12 & $(.67,1.21)$ & .95 & .07 & $(.79,1.14)$ \\
\hline \multicolumn{10}{|l|}{ Living in an owned house (reference) } \\
\hline \multicolumn{10}{|l|}{ Living arrangement } \\
\hline Living with grandparents & .55 & .17 & $(.30,1.02)$ & .75 & .18 & $(.37,1.49)$ & 1.02 & .20 & $(.64,1.60)$ \\
\hline \multicolumn{10}{|l|}{ Living with parents (reference) } \\
\hline \multicolumn{10}{|l|}{ Urban/rural hukou } \\
\hline Rural & 1.17 & .09 & $(.88,1.56)$ & $1.31 *$ & .13 & $(1.00,1.74)$ & .92 & .12 & $(.78 .1 .09)$ \\
\hline \multicolumn{10}{|l|}{ Urban (reference) } \\
\hline \multicolumn{10}{|l|}{ Parental education level } \\
\hline Middle school or lower & 1.13 & .17 & $(.80,1.59)$ & $1.42^{*}$ & .17 & $(1.01,2.57)$ & 1.16 & .24 & $(.94,1.43)$ \\
\hline \multicolumn{10}{|l|}{ Bachelor's or higher (reference) } \\
\hline \multicolumn{10}{|l|}{ Maternal education level } \\
\hline Middle school or lower & .75 & .17 & $(.53,1.07)$ & 1.18 & .19 & $(.79,1.77)$ & 1.01 & .18 & $(.76,1.83)$ \\
\hline Bachelor's or higher (reference) & & & & & & & & & \\
\hline
\end{tabular}

(1) bullying involvement was divided into four categories, and the category for reference is "not-involved"; $(2){ }^{*} p<0.05,{ }^{* *} p<0.01 ;{ }^{* * *} p<0.001$

several previous studies, a large proportion of internalmigrants in China are from rural areas [23]. Because of this, there is a noticeable difference in bullying perception between rural and urban adolescent. A large proportion of rural adolescents (especially males) regard bullying others as a status symbol (i.e. masculine capital), while urban adolescents usually interpret bullying as an act of "lack of self-restraint" and "rudeness" [34]. This differentiation in social values may also explain why migrant adolescents were more likely to be bullies in this study. In addition, adolescents who have a less educated father (but not mother) were also more likely to be bullies in this study. Parental education level has long been regarded as an important socio-economic factor, considering the significant effect of socio-economic characteristics on adolescents' social behaviors; the association between fathers' education level and bullying may partly be due to fathers' dominant role in maintaining the family's socio-economic status, which the child mimics [35].

Contrary to our original hypothesis, adolescents who lived with their grandparents did not have a higher or lower likelihood of being bullies. This result is inconsistent with some of the previous research that suggests cohabitating with grandparents could be positively associated with adolescents' social adjustments. Previous research [11] evaluated how grandparents' involvement, but not living only with grandparents, could affect the possibility of involvements in bullying for adolescents. However, the family dynamics could be quite different when grandparents' are only involved with the child's upbringing, but not living with the child. The child living only with their grandparents could possibly explain the inconsistency presented in research results. Future studies are required to clarify the role of grandparents in preventing or exacerbating bullying at school, with special care paid to exploring the differences in family composition (living with grandparents and parents, living only with grandparents, living with parents and receiving care from grandparents).

It is important to note that all the aforementioned family demographic characteristics were not associated with a high risk of being victims of bullying. Bullies (or bully/victims) are different from victims in terms of behavioral patterns. Bullying perpetration (or perpetration-victimization) has been conceptualized as "being proactively aggressive", referring to "... cold blooded and goal-directed bullying behaviors" [36]. Looking at the current results of this study, adolescents from 
Table 4 Odds ratios for bystander intervention

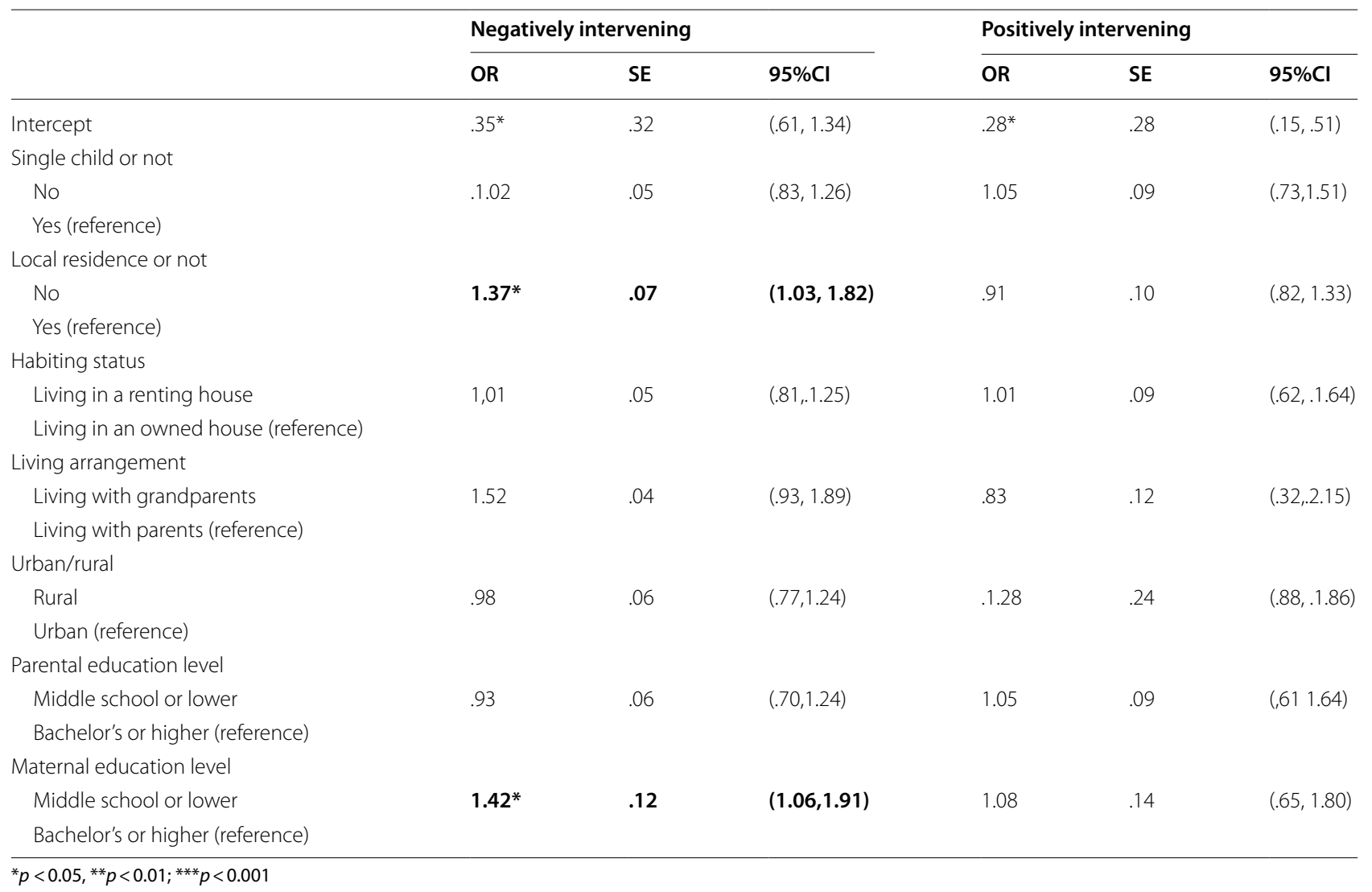

disadvantageous families had a higher risk of being proactive rather than reactive bullies. Further research is needed to explore the different relations between family demographics and proactive or reactive bullying at school.

In our study, adolescents from migrant families also had a higher likelihood of negatively reacting to those being bullied (e.g. teasing). According to previous research [37], adolescents with better social skills (such as high empathy, high self-control etc.) are more likely to intervene and provide help when they witness bullying scenarios. Therefore, having better social skills might explain the association between family economic status and intervention as a bystander. The results from our study are consistent with previous findings that adolescents from low economic backgrounds have a higher rate of delinquency [35]. Adolescents then with highly-educated parents are less likely to experience negative emotions (i.e. fear of school) than their counterparts. This indicated that both parental and maternal education levels could be a protective factor against bullying.

There are several limitations to the current research. First, all participants were from Suzhou, an economically advantageous city in Eastern China. Considering the main focus is on socio-demographic factors, such sampling methods may render the results prone to selection bias. Second, considering the cross-sectional nature of the current research, only correlations between bullying and the demographic factors could be explored. Longitudinal design should be adopted in future studies to examine causal relationships between the two constructs. Third, the measurements of some bullying-related constructs were simplified for concision. For example, only two forms of bullying (i.e. verbal/physical) were measured in the current research, with other forms, such as cyber-bullying and social isolation being unexamined. Also, the widely recognized features of school bullying (such as intention and power imbalances) were not considered appropriately in the current research. Participants may misunderstand the complex concept of bullying. For example, they could possibly regard some conflicts without power imbalances (e.g. arguments or fights) as bullying behaviors, which is not the aim of the current research. Future studies should explore how family demographic factors relate to a wide range of different forms of bullying, with a more accurate definition. Considering the complexity of behavioral patterns of bystanders, the current categorization (non-reaction, 
Table 5 Odds ratios for reactions to being bullied (fear of being bullied)

\begin{tabular}{|c|c|c|c|c|c|c|}
\hline & \multicolumn{3}{|c|}{ Fear of being bullied (never versus sometimes) } & \multicolumn{3}{|c|}{ Fear of being bullied (never versus usually) } \\
\hline & $\begin{array}{l}\text { Odds Ratios } \\
\text { (ORs) }\end{array}$ & Standard Error & $95 \% \mathrm{Cl}$ & $\begin{array}{l}\text { Odds Ratios } \\
\text { (ORs) }\end{array}$ & Standard Error & $95 \% \mathrm{Cl}$ \\
\hline Intercepts & $.09^{* *}$ & .28 & $(.01, .72)$ & $.07^{* *}$ & .35 & $(.04, .15)$ \\
\hline \multicolumn{7}{|l|}{ Single child or not } \\
\hline No & 1.06 & .08 & $(.86,1.32)$ & .64 & .12 & $(.41, .99)$ \\
\hline \multicolumn{7}{|l|}{ Yes (reference) } \\
\hline \multicolumn{7}{|l|}{ Local residence or not } \\
\hline No & $1.86^{*}$ & .08 & $(1.09,1.97)$ & 1.46 & .13 & $(.92,2.32)$ \\
\hline \multicolumn{7}{|l|}{ Yes (reference) } \\
\hline \multicolumn{7}{|l|}{ Habiting status } \\
\hline Living in a renting house & .83 & .09 & $(.63,1.08)$ & .89 & .08 & $(.53,1.56)$ \\
\hline \multicolumn{7}{|l|}{ Living in an owned house (reference) } \\
\hline \multicolumn{7}{|l|}{ Living arrangement } \\
\hline Living with grandparents & .79 & .21 & $(.44,1.41)$ & 1.97 & .24 & $(.27,2.27)$ \\
\hline \multicolumn{7}{|l|}{ Living with parents (reference) } \\
\hline \multicolumn{7}{|l|}{ Urban/rural } \\
\hline Rural & 1.04 & .09 & $(.75,1.26)$ & .74 & .14 & $(.48,1.15)$ \\
\hline \multicolumn{7}{|l|}{ Urban (reference) } \\
\hline \multicolumn{7}{|l|}{ Parental education level } \\
\hline Middle school or lower & .86 & .11 & $(.65,1.16)$ & .92 & .14 & $(.48,1.71)$ \\
\hline \multicolumn{7}{|l|}{ Bachelor's or higher (reference) } \\
\hline \multicolumn{7}{|l|}{ Maternal education level } \\
\hline Middle school or lower & $1.33^{*}$ & .12 & $(1.00,1.87)$ & $1.39 *$ & .11 & $(1.01,1.99)$ \\
\hline Bachelor's or higher (reference) & & & & & & \\
\hline
\end{tabular}

positively intervening, and negatively intervening) may not capture all possible ways of intervening behaviors in a bullying scenario. Also, among all the possible consequences of being bullied, we only adopted "fear of bullied" as the indicator. Although fear of being bullied has been identified as the most direct consequence of school bullying, other long-term consequences (such as depression and maladjustment) should further be incorporated in future research.

Finally, the current research adopted a non-anonymous survey format during data collection. Anonymous survey format is the preference for most existing studies on bullying, with the assumption that participants may reveal more truthful answers when personal information is not required. However, previous evidence on how anonymity might influence research validity is mixed. Some researchers propose that an anonymous survey could encourage participants to "exaggerate or make irresponsible responses" [38]. There is also evidence showing that results from anonymous and non-anonymous bullying surveys were not statistically different [39, 40]. O'Malley and colleagues [41] found that the assurance of confidentiality (but not anonymity) could be sufficient to obtain good validity, which was the practice in this study. Based on these results, the effects of anonymity could be mixed. Anonymity should be taken into consideration and multi-methods (i.e. peer-nomination, teacher assessment) should be used to evaluate bullying experiences in future studies.

\section{Conclusions}

Our research discovered that family household demographic characteristics were related to the constructs of adolescents' bullying at school. These risk characteristics can be used to inform practical guidance for school consolers about which students are at the higher risk of being involved in bullying and which students are at risk from suffering from negative consequences of being bullied. In particular, although abundant evidence has shown that children with or without siblings behave in many different ways [37], being an only child was not associated with any bullying-related constructs in the current research. Future research efforts are 
required to explore the relations between being an only child and bullying at school, with specific attention paid to generational changes that will result from the two, and now three-child policy in China.

\section{Supplementary Information}

The online version contains supplementary material available at https://doi. org/10.1186/s12889-021-12367-3.

\section{Additional file 1.}

\section{Acknowledgements}

Not applicable.

\begin{abstract}
Authors' contributions
Haoran Wang wrote the main manuscript; Guosheng Wang finished the main processing of data analysis. Yuanyuan Wang and Yong Yang designed the study. Yuanyuan Wang and Amanda Wilson helped with the interpretation of the data and revised the manuscript. Tingting Jin, Longjun Zhu, Renjie Yu, Shuilan Wang, Weijia Yin, Huihui Song, Shun Li, Qiufang Jia, Xiaobin Zhang collected the data and helped in the data processing. Yong Yang controlled the quality of the whole research. The author(s) read and approved the final manuscript.
\end{abstract}

\section{Funding}

The current study received financial support from the following programs: (1) Suzhou Health Talent Project (No. Gsws2020096 to Y.Y.); (2) Young Medical Talent of Jiangsu Province (No. Qnrc2016229 to Y.Y.); (3) Suzhou Municipal Sci-Tech Bureau Program (No. Ss2019009 to Q.F.J); (4) Suzhou clinical Medical Center for mood disorders (No.Szlcyxzx202109). All the funding was used during the data collecting process.

\section{Availability of data and materials}

The datasets used during the current study is available from the corresponding author on reasonable request.

\section{Declarations}

\section{Ethics approval and consent to participate}

We have confirmed that all the methods and procedures were performed in accordance with the relative guidelines and regulations. Assent was obtained from participates and informed consent was obtained from their main guardian prior to the pencil-and-paper questionnaires being filled in at school. Teachers were involved in obtaining parental consent, this included passive parental consent where an information sheet was given to parents/quardians allowing them the opportunity to consider whether their child should take part in and providing them the opportunity to inform the teacher if they did not want their child to participate. If the parent did not inform the teacher that they objected to the research, it was passively assumed that the teacher had their consent for the child to participate (Hollmann \& McNamara, 1999). The entire research procedure also received approval from Ethics Committee of Suzhou Guangji Hospital (SGLS2017-037).

\section{Consent for publication}

Not applicable.

\section{Competing interests}

The authors declare that they have no competing interests.

\section{Author details}

'Dalian Seventh People's Hospital, 179\# Lingshui Road, Dalian 116023, China.

2 Division of Psychology, Faculty of Health and Life Sciences, De Montfort University, Leicester, UK. ${ }^{3}$ Suzhou Guangji Hospital, 11\# Guangqian Road, Suzhou 215137, China. ${ }^{4}$ Suzhou No.1 High School of Jiangsu Province, , 279\# Gongyuan Road, Suzhou 215011, China.
Received: 26 May 2021 Accepted: 30 November 2021

Published online: 11 December 2021

\section{References}

1. Kaess M. Bullying: peer-to-peer maltreatment with severe consequences for child and adolescent mental health. Eur Child Adolesc Psychiatry. 2018:27(8):945-7.

2. Han Z, Zhang G, Zhang H. School bullying in urban China: prevalence and correlation with school climate. Int J Environ Res Public Health. 2017;14(10):1116

3. Jenkins LN, Fredrick SS, Wenger J. Peer victimization and social-emotional outcomes: The role of teacher and peer support. Aggress Behav. 2018;44(2):176-84.

4. Bandeira CDM, Hutz CS. Bullying: prevalence, implications and gender differences. Psicologia Escolar e Educacional. 2012;16:35-44.

5. Deoliveira WA, Luizsilva J, Rodríguesfernandez JE, Dossantos MA, lossisilva MA. Family interactions and the involvement of adolescents in bullying situations from a bioecological perspective. Estudos de Psicologia (Campinas). 2020;37(3).

6. Tucker CJ, Finkelhor D, Turner H. Family predictors of sibling versus peer victimization. J Div Fam Psychol Am Psychol Assoc (Division 43). 2020;34(2):186-95.

7. Chen JK, Wang SC, Chen YW, et al. Family Climate, Social Relationships With Peers and Teachers at School, and School Bullying Victimization Among Third Grade Students in Elementary Schools in Taiwan. Sch Ment Health. 2021;13:452-61.

8. Oliveira W, Silva J, Fernández JE, Santos M, Caravita SCS, Silva M. Family interactions and the involvement of adolescents in bullying situations from a bioecological perspective. Estudos de Psicologia (Campinas). 2020 https://doi.org/10.1590/1982-0275202037e180094.

9. Mulvey KL, Gönültaş S, Goff E, Irdam G, Carlson R, DiStefano C, et al. School and family factors predicting adolescent cognition regarding bystander intervention in response to bullying and victim retaliation. J Youth Adolesc. 2019;48(3):581-96.

10. Vargas AEO, Monjardín MDRM. Multifactorial impact of family environment in bullying among boys and girls. Psicologia Escolar e Educacional. 2019;23.

11. Khalid S, Ahmed F, Imdad M. Grandparenting and adolescents' personality development. Int Proc Econ Dev Res. 2012;48:143-7.

12. Zhang F, Wu Y. Living with grandparents: Multi-generational families and the academic performance of grandchildren in China. Chin J Soc. 2021:7(3):413-43

13. Nansel TR. Cross-national consistency in the relationship between bullying behaviors and psychosocial adjustment. Arch Pediatr Adolesc Med. 2004;158(8):730.

14. Qiang F, Lamb VL. School bullying, family structure and socioeconomic status in the United States from 1989 to 2009: repetitive trends and persistent disadvantage; 2012

15. Ataei T, Zeighami R, Azh N, Mafi M. Factors affecting adolescents' risktaking in single-child families. Soc Health Behav. 2019;2(4):151.

16. Dey B, Roy K, Shepo J. Children behavior problem and academic achievement as a function of family structure, residence and types of school. Hum Dev Soc Life. 2016.

17. Ackerman BP, D'Eramo KS, Umylny L, Schultz D, Izard CE. Family structure and the externalizing behavior of children from economically disadvantaged families. J Fam Psychol. 2001;15(2):288.

18. Fung A. The significance of family structure in internalizing (anxious/ depressed) and externalizing (aggressive/delinquent) problems among Chinese adolescents. Appl Res Qual Life. 2021;(1).

19. Jiang S, Li C, Fang X. Socioeconomic status and children's mental health: understanding the mediating effect of social relations in mainland China J Commun Psychol. 2018;46(2):213-23.

20. Annalaura, Giada, Ludovica, Ersilia Parents, family characteristics and bullying behavior: A systematic review, Aggression and Violent Behavior. 2019:45:41-50.

21. Hesketh T, Lu L, Xing ZW. The effect of china's one-child family policy after 25 years. N Engl J Med. 2005;353(11):1171-6.

22. Zeng $Y$, Hesketh $T$. The effects of china's universal two-child policy. Lancet. 2016;388(10054):1930-8. 
23. Cui K, To SM. Migrant status, social support, and bullying perpetration of children in mainland China. Child Youth Serv Rev. 2019;107:104534.

24. Bertram $\mathrm{H}$. The multi-local and multi-generational family. 2004. https:// doi.org/10.1057/978-1-137-52099-9_3. Accessed 1 June 2015.

25. Bozda F, Bilge F. Self-construals, adjustment problems and coping styles of internal migrant and non-migrant adolescents. Curr Psychol. 2021:4:1-15.

26. Tatum KL, Valenzuela JM, Amirniroumand RA, Brochu PM. Parents' Perceptions of and Responses to School-Based Body Mass Index Screening Programs-A Systematic Review. J Sch Health. 2021;91(4):331-44.

27. Pyhnen V, Juvonen J, Salmivalli C. Standing up for the victim, siding with the bully or standing by? Bystander responses in bullying situations. Soc Dev. 2012;21:722-41.

28. Solberg M, Olweus D. Prevalence Estimation of School Bullying with the Olweus Bully/Nictim Questionnaire. Aggress Behav. 2003;29:239-68.

29. Sommet N, Morselli D. Keep calm and learn multilevel logistic modeling: a simplified three-step procedure using Stata, R, Mplus, and SPSS. Int Rev Soc Psychol. 2017;30(1):article 203-18.

30. Cohen J. Statistical power analysis for the behavioral sciences. New York: Academic Press; 1977. p. 109-43.

31. Neil T, Dieter W. Socioeconomic status and bullying: a meta-analysis. Am J Public Health. 2014;104(6):e48-59.

32. Silbereisen R, Chen X. Social Change and Human Development - Concept and Results; 2010

33. Axpe I, Rodríguez-Fernández A, Goñi E, Antonio-Agirre I. Parental Socialization Styles: The Contribution of Paternal and Maternal Affect/Communication and Strictness to Family Socialization Style. Int J Environ Res Public Health. 2019;16(12):2204.

34. Nickerson AB, Aloe AM, Livingston JA, Feeley TH. Measurement of the bystander intervention model for bullying and sexual harassment. J Adolesc. 2014;37:391-400.

35. Jiang $S$, Dong L, Jiang C. Examining the link between economic strain and adolescent social behavior: roles of social bonds and empathy. J Adolesc. 2020;84:1-10.

36. Camodeca M, Goossens FA, Terwogt MM, Schuengel C. Bullying and victimization among school-age children: stability and links to proactive and reactive aggression. Soc Dev. 2002;11(3):332-45.

37. Magklara K, Skapinakis P, Gkatsa T, Bellos S, Araya R, Stylianidis S. Bullying behavior in schools, socioeconomic position and psychiatric morbidity: a cross-sectional study in late adolescents in Greece. Chin Med. 2012;6:1.

38. Ahmad Y, Smith PK. Behavioral measures: bullying in schools. Newsl Assoc Child Psychol Psychiatry. 2001;12:26-7.

39. Chan HFJ, Myron R, Crawshaw M. The efficacy of non-anonymous measures of bullying. Sch Psychol Int. 2005;26:443-58.

40. Dewey C, Sharmila B, Mehta. Counselor confirmation of middle school student self-reports of bullying victimization. Prof Sch Couns. 2018;14(4).

41. O'Malley PM, Johnston LD, Bachman JG, Schulenberg JE. A comparison of confidential versus anonymous survey procedures: effects on reporting of drug use and related attitudes and beliefs in a national study of students. J Drug Issues. 2000;30:35-54

\section{Publisher's Note}

Springer Nature remains neutral with regard to jurisdictional claims in published maps and institutional affiliations.

Ready to submit your research? Choose BMC and benefit from:

- fast, convenient online submission

- thorough peer review by experienced researchers in your field

- rapid publication on acceptance

- support for research data, including large and complex data types

- gold Open Access which fosters wider collaboration and increased citations

- maximum visibility for your research: over $100 \mathrm{M}$ website views per year

At BMC, research is always in progress.

Learn more biomedcentral.com/submissions 